\title{
Rapid PCR Detection of Mycoplasma hominis, Ureaplasma urealyticum, and Ureaplasma parvum
}

\author{
Scott A. Cunningham, ${ }^{1}$ Jayawant N. Mandrekar, ${ }^{2}$ Jon E. Rosenblatt, ${ }^{1}$ and Robin Patel ${ }^{1,3}$ \\ ${ }^{1}$ Division of Clinical Microbiology, Department of Laboratory Medicine and Pathology, Mayo Clinic, Rochester, MN 55905, USA \\ ${ }^{2}$ Division of Biomedical Statistics and Informatics, Department of Health Science Research, Mayo Clinic, Rochester, MN 55905, USA \\ ${ }^{3}$ Division of Infectious Diseases, Department of Medicine, Mayo Clinic, Rochester, MN 55905, USA
}

Correspondence should be addressed to Robin Patel; patel.robin@mayo.edu

Received 5 November 2012; Accepted 30 January 2013

Academic Editor: Sam R. Telford

Copyright @ 2013 Scott A. Cunningham et al. This is an open access article distributed under the Creative Commons Attribution License, which permits unrestricted use, distribution, and reproduction in any medium, provided the original work is properly cited.

\begin{abstract}
Objective. We compared laboratory developed real-time PCR assays for detection of Mycoplasma hominis and for detection and differentiation of Ureaplasma urealyticum and parvum to culture using genitourinary specimens submitted for M. hominis and Ureaplasma culture. Methods. 283 genitourinary specimens received in the clinical bacteriology laboratory for M. hominis and Ureaplasma species culture were evaluated. Nucleic acids were extracted using the Total Nucleic Acid Kit on the MagNA Pure 2.0. $5 \mu \mathrm{L}$ of the extracts were combined with $15 \mu \mathrm{L}$ of each of the two master mixes. Assays were performed on the LightCycler 480 II system. Culture was performed using routine methods. Results. M. hominis PCR detected 38/42 M. hominis culture-positive specimens, as well as 2 that were culture negative (sensitivity, 90.5\%; specificity, 99.2\%). Ureaplasma PCR detected 139/144 Ureaplasma culture-positive specimens, as well as 9 that were culture negative (sensitivity, 96.5\%; specificity, 93.6\%). Of the specimens that tested positive for Ureaplasma species, U. urealyticum alone was detected in 33, U. parvum alone in 109, and both in 6. Conclusion. The described PCR assays are rapid alternatives to culture for detection of M. hominis and Ureaplasma species, and, unlike culture, the Ureaplasma assay easily distinguishes U. urealyticum from parvum.
\end{abstract}

\section{Introduction}

Mycoplasma hominis, Ureaplasma urealyticum, and Ureaplasma parvum are small, fastidious bacteria belonging to the Mollicutes class. They lack a cell wall (preventing staining with Gram stain) and are not sensitively detected on routine bacterial cultures. Optimal recovery requires specialized media and growth conditions. There are several human pathogens in the genera Mycoplasma and Ureaplasma which are responsible for a variety of clinical manifestations involving multiple body systems [1]. M. hominis causes septic arthritis and postpartum fever and has been associated with pelvic inflammatory disease and bacterial vaginosis [2]. Ureaplasma species can cause acute urethritis and have been associated with bacterial vaginosis, preterm birth, and neonatal respiratory disease $[1,3]$.

Although M. hominis and Ureaplasma species can be cultured, this requires technical skill for interpretation of microscopic colonies and takes two to five days. U. urealyticum was the only Ureaplasma species until 2002, when U. parvum was described [4]. The two are not distinguished based on culture characteristics alone. Real-time PCR detection of these microorganisms from clinical samples circumvents technical issues related to culture and shortens turnaround time for detection and identification.

Few real-time PCR assays and associated studies have been described for M. hominis. A real-time PCR assay targeting $M$. hominis gap identified two positive cervical swabs from women being evaluated for infertility [5]. 153 urogenital specimens were tested with a real-time PCR assay targeting M. hominis yidC, of which 45 were PCR- and culture positive and 10 PCR positive only [6]. Finally, extragenital M. hominis infection was diagnosed in three patients using a real-time PCR assay targeting the $M$. hominis $16 \mathrm{~S}$ ribosomal RNA gene [7]. 
TABLE 1: Primers and probes.

\begin{tabular}{|c|c|c|}
\hline \multicolumn{3}{|c|}{ Mycoplasma hominis tuf (set number 793, TIB MolBio, Aldelphia, NJ; 10X concentration) ${ }^{\mathrm{a}}$} \\
\hline \multirow{2}{*}{ Primers } & tuf $193 \mathrm{~F}$ & $5^{\prime}$ AATTGATATGTTTAAAGATGATGAAAGAGA $3^{\prime}$ \\
\hline & tuf $193 \mathrm{R}$ & $5^{\prime}$ TGTATCAACAGCATCCATTAATTCC $3^{\prime}$ \\
\hline \multirow{2}{*}{ Probes } & tuf $193 \mathrm{fl}^{\mathrm{b}}$ & $5^{\prime}$ GACGTAAGAAGCCTTCTATCAGAATATGGT FITC 3' \\
\hline & tuf $193 \mathrm{iLC} 610^{\mathrm{c}}$ & 5’ Red610 TGATGGTGACAATGCTCCTATTATTGCTGGTTC PO4 3’ \\
\hline \multicolumn{3}{|c|}{ Ureaplasma species ureC (set number 684 , TIB MolBio; $10 \mathrm{X}$ concentration) ${ }^{\mathrm{d}}$} \\
\hline \multirow{3}{*}{ Primers } & ureC $158 \mathrm{~F}$ & $5^{\prime}$ CCTGCTTCGTTTAATGTATCTG 3' \\
\hline & ureC $158 \mathrm{R}$ & $5^{\prime}$ GAAGATCCAATCTTTGAACAAATCGTA $3^{\prime}$ \\
\hline & ureC 158R5 & 5' GAAGATCCAATCTTTGAACAAATTGCT $3^{\prime}$ \\
\hline \multirow{2}{*}{ Probes } & ureC $158 \mathrm{fl}^{\mathrm{b}}$ & 5' AGCAACTGTTAATGCTAAGTCAATAGCGTTTCCTG FITC 3’ \\
\hline & ureC $158 \mathrm{iLC} 610^{\mathrm{c}}$ & $5^{\prime}$ Red610 GCCCCTCAGTCTTCGTGAATCTTAAGACCACAAGC PO4 3' \\
\hline
\end{tabular}

\footnotetext{
a tuf target corresponds to 66720-66912 of GenBank accession number FP236530.

${ }^{\mathrm{b}}$ Labeled with fluorescein on $3^{\prime}$ end.

${ }^{c}$ Labeled with LC610 on $5^{\prime}$ end and a phosphate on $3^{\prime}$ end.

${ }^{\mathrm{d}}$ ure $\mathrm{C}$ target corresponds to 527786-527943 of GenBank accession number CP001184.
}

There has been more work on real-time PCR assays for Ureaplasma species, although some have described assays but have not evaluated clinical specimens or clinical isolates [8]. A real-time PCR assay that detects and distinguishes $U$. urealyticum from parvum was described but used to assess 87 vaginal swabs [9]. Tang et al. used a real-time PCR assay that detects and distinguishes U. parvum and urealyticum to test 346 genitourinary swabs; 120 were positive for the former and 21 for the latter, including 5 positive for both [10]. Finally, Vancutsem et al. used a real-time PCR assay for detection and differentiation of $U$. urealyticum and parvum to evaluate 300 lower genital tract specimens; 132 were culture positive, of which all plus an additional 19 were PCR-positive (19, $U$. urealyticum; 120, U. parvum; 12, Ureaplasma species) [11].

Herein, we present one real-time PCR assay for the detection of $M$. hominis and another for the detection and differentiation of Ureaplasma species and report results of these assays on 283 genitourinary specimens in comparison to culture.

\section{Materials and Methods}

2.1. Clinical Specimens. 283 genitourinary specimens (swabs, urine) submitted to the Mayo Clinic Clinical Microbiology Laboratory in transport medium (e.g., UTM, M5) for $M$. hominis and Ureaplasma culture were evaluated. No clinical data associated with these specimens was available. This study was approved by the Mayo Clinic Institutional Review Board.

2.2. Mycoplasma hominis Culture. Samples were placed into arginine broth, incubated at $35^{\circ} \mathrm{C}$, and monitored four times daily for up to five days. Color change (indicating an alkaline $\mathrm{pH}$ shift) in the arginine broth prompted subculture of $50 \mu \mathrm{L}$ to an A7 agar plate. Plates were incubated anaerobically at $35^{\circ} \mathrm{C}$ for up to five days and examined daily with an inverted light microscope for "fried egg" morphology colonies.

2.3. Ureaplasma Culture. Samples were placed into U9 broth, incubated at $35^{\circ} \mathrm{C}$, and monitored four times daily for up to five days. A color change (indicating an alkaline $\mathrm{pH}$ shift) in the U9 broth prompted subculture of $100 \mu \mathrm{L}$ to an A7 agar plate. Plates were incubated anaerobically at $35^{\circ} \mathrm{C}$ for up to 48 hours and examined with an inverted light microscope for small, circular to irregular colonies growing into the surface of the agar, with a surrounding red zone. Confirmation of Ureaplasma species was indicated by golden-brown stained colonies with the addition of $0.167 \mathrm{M} \mathrm{CO}\left(\mathrm{NH}_{2}\right)_{2}$ and $0.04 \mathrm{M}$ $\mathrm{MnCl}_{2}$ in water.

2.4. Sample Processing for PCR. Samples were vortexed and $200 \mu \mathrm{L}$ transferred to a MagNA Pure sample cartridge (Roche Applied Science, Indianapolis, IN). DNA extraction was performed on the MagNA Pure LC 2.0 using the MagNA Pure LC Total Nucleic Acid Isolation Kit (Roche Applied Science) with a final elution volume of $100 \mu \mathrm{L}$.

2.5. Polymerase Chain Reaction Assay. Primers and probes (Table 1) were designed using the LightCycler Probe Design Software, version 2.0 (Roche Diagnostics, Indianapolis, IN, USA) and DNA Workbench, version 5.7.1 (CLC Bio, Cambridge, MA, USA). Positive control plasmids were constructed for the three target-specific genes (Table 1) using the pCR 2.1 TOPO TA Cloning Kit (Invitrogen Corporation, Carlsbad, CA, USA). Sources for the inserted target sequences were M. hominis ATCC 23114, U. urealyticum ATCC 27618, and U. parvum ATCC 27815D. Plasmids were purified using the High Pure Plasmid Isolation Kit (Roche Applied Science). Sizes of the cloned inserts were confirmed by EcoR1 digestion. Plasmid inserts were sequenced using M13 forward and reverse primers included in the cloning kit, to confirm proper insert orientation. Plasmids were diluted in Tris-EDTA buffer ( $\mathrm{pH}$ 8.0) and stored at $4^{\circ} \mathrm{C}$.

The two assays were independently optimized on the LightCycler 480 II platform employing LightCycler 480 Software version 1.5 (Roche Applied Science). $15 \mu \mathrm{L}$ of PCR master mix, containing final concentrations of $1 X$ Roche Genotyping Master (Taq DNA polymerase, PCR reaction 
buffer, deoxyribonucleoside triphosphate with dUTP substituted for dTTP and $1 \mathrm{mM} \mathrm{MgCl}$ ), $1 \mathrm{mM}$ (additional) $\mathrm{MgCl}_{2}$, and $1 \mathrm{X}$ of each of the LightCycler primer-probe sets (Table 1) were added to a 96-well LightCycler 480 plate. Extracted nucleic acid $(5 \mu \mathrm{L})$ was then added to each well. The cycling program was as follows: denaturation at $95^{\circ} \mathrm{C}$ for $10 \mathrm{~min}$; amplification for 45 cycles of $10 \mathrm{~s}$ at $95^{\circ} \mathrm{C}, 15 \mathrm{~s}$ at $55^{\circ} \mathrm{C}$ (single acquisition), and $15 \mathrm{~s}$ at $72^{\circ} \mathrm{C}$; melting curve analysis for $30 \mathrm{~s}$ at $95^{\circ} \mathrm{C}, 10 \mathrm{~s}$ at $59^{\circ} \mathrm{C}, 15 \mathrm{~s}$ at $45^{\circ} \mathrm{C}\left(\right.$ ramp rate of $\left.0.1^{\circ} \mathrm{C} / \mathrm{s}\right)$, and $0 \mathrm{~s}$ at $80^{\circ} \mathrm{C}$ (ramp rate of $0.14^{\circ} \mathrm{C} / \mathrm{s}$ and continuous acquisition); and cooling for $30 \mathrm{~s}$ at $40^{\circ} \mathrm{C}$. Positive and negative controls were included in each run. The positive control consisted of the abovementioned plasmids in S.T.A.R. buffer : sterile water $(1: 1)$ at a concentration of 1,000 targets/ $\mu \mathrm{L}$. The negative control consisted of 1,000 colony forming units of Escherichia coli ATCC 25922 S.T.A.R. buffer: sterile water $(1: 1)$ at a concentration of 1,000 targets/ $\mu \mathrm{L}$.

2.6. Polymerase Chain Reaction Sensitivity and Specificity. Predicted amplified product, primer, and probe sequences were subjected to BLAST searches using the National Center for Biotechnology Information (NCBI) genomic database (http://www.ncbi.nlm.nih.gov/). Analytical sensitivity was assessed by spiking a series of six tenfold dilutions of quantified genomic DNA from $M$. hominis ATCC 23114, $U$. urealyticum ATCC 27816, and U. parvum ATCC 27815D into genitourinary samples. Each dilution was extracted in triplicate and each extract was assayed in duplicate. The limit of detection was the lowest dilution where all six replicates were detected. Inclusivity and cross-reactivity were assessed using a panel organisms (Table 2), including 16 members of the Mollicutes class.

Clinical sensitivity and specificity were assessed by assaying the aforementioned clinical specimens and comparing results to those of culture. Discordant samples were tested courtesy of Dr. Stellrecht, at an independent clinical laboratory (Albany Medical Center) with a previously described assay [12].

The ability of the Ureaplasma assay to differentiate urealyticum from parvum was assessed as follows. Cultured isolates from clinical samples were directly subjected to PCR with species differentiation based on melting curve analysis; sequence variations underlying the probed regions of $U$. urealyticum and parvum result in separation of the melting temperature of the two species (Figures 1 and 2). Results were compared to those of a previously described conventional PCR speciation method targeting the multiplebanded antigen using primers UMS-57 and UMA222 for $U$. parvum and UMS-170 and UMA263 for U. urealyticum [13].

2.7. Statistical Analysis. Assessment of the assays' sensitivity and specificity, with associated $95 \%$ confidence intervals (CI), compared to that of culture for M. hominis and Ureaplasma species was made using SAS software version 9.1 (SAS, INC, Cary, NC, USA).

\section{Results}

3.1. Polymerase Chain Reaction Sensitivity and Specificity. The analytical sensitivity of both assays was 100 genome copies/ $\mu \mathrm{L}$

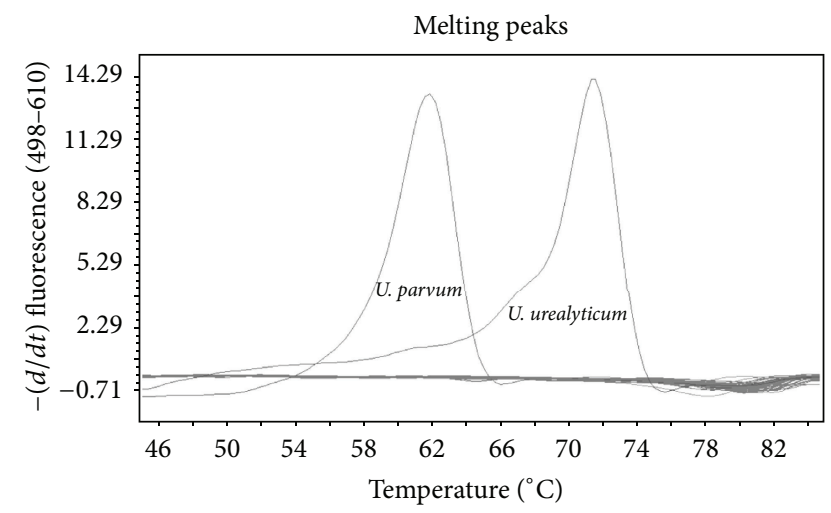

Figure 1: Melting curves of Ureaplasma urealyticum and Ureaplasma parvum.

genitourinary specimen. Amplified product, primer, and probe sequences were subjected to NCBI database searches using BLAST software; no significant homology was noted outside of the genera targeted by these assays. Nucleic acid material from members of the Mollicutes class, excluding M. hominis and the Ureaplasma species, was not detected (Table 2).

3.2. Clinical Sensitivity and Specificity. The M. hominis PCR assay had a clinical sensitivity and specificity of $90.7 \%$ (95\% CI: 77.4\%, 97.3\%) and 99.2\% (95\% CI: 97.0\%, 99.9\%), respectively (Table 3 ). The 6 discordant results were tested at the Albany Medical Center using an assay targeting the 16S ribosomal RNA gene; [12] both PCR positive/culturenegative specimens were PCR positive, and three of four PCR negative/culture-positive specimens were PCR negative.

The Ureaplasma PCR assay had a clinical sensitivity and specificity of $96.5 \%$ (95\% CI: 92.1\%, 98.9\%) and 93.8\% (95\% CI: $88.1 \%, 97.0 \%$ ), respectively (Table 3). The 14 discordant results were tested at Albany Medical Center; [12] five of nine specimens that were PCR positive/culture negative were PCR positive, and all five specimens that were PCR negative/culture positive were PCR negative. Of the specimens that tested positive for Ureaplasma species by PCR and were culture positive, $U$. urealyticum alone was detected in 28, U. parvum alone in 109, and both in 2. Among the PCR positive/culture-negative specimens, U. urealyticum was detected in 3 and $U$. parvum in 6.

Thirty-one culture isolates of Ureaplasma species were tested with the Ureaplasma assay and a previously reported PCR method that differentiates between the two species [13]. The reference method yielded species-level identification for 20 isolates, including 4 U. urealyticum and $16 U$. parvum, with identical results to the assay described herein. The remaining 11 isolates were speciated by the assay described herein but not by the reference method; they were confirmed to be Ureaplasma species by partial $16 \mathrm{~S}$ ribosomal RNA gene sequencing [14]. All partial 16S ribosomal RNA gene sequences were identical to one another and were perfect matches to bases 145,365 through 145,845 of GenBank AF222894.1 
TABLE 2: Cross-reactivity and inclusivity panel. Only Mycoplasma hominis, Ureaplasma parvum, and Ureaplasma urealyticum were detected (by the appropriate assays).

\begin{tabular}{|c|c|c|c|}
\hline Organism & $\begin{array}{l}\text { Accession no. or } \\
\text { source }\end{array}$ & Organism & $\begin{array}{l}\text { Accession no. or } \\
\text { source }\end{array}$ \\
\hline Acholeplasma laidlawii & ATCC 23206 & Entamoeba histolytica & ATCC 30459 \\
\hline Acinetobacter baumannii & ATCC 19606 & Entamoeba moshkovskii & ATCC 30042 \\
\hline $\begin{array}{l}\text { Acinetobacter } \\
\text { lwoffi//haemolyticus }\end{array}$ & QC Strain & Enterobacter cloacae & ATCC 13047 \\
\hline Actinomyces odontolyticus & ATCC 17929 & Enterococcus faecalis & ATCC19433U \\
\hline Aeromonas hydrophila & CAP-D-1-82 & Enterococcus faecium & ATCC 19434 \\
\hline Arcanobacterium haemolyticum & ATCC 9345 & Escherichia coli & ATCC 25922 \\
\hline Arcanobacterium pyogenes & ATCC 19411 & Escherichia coli O142:K86(B):H6 & ATCC 23985 \\
\hline Parabacteroides distasonis & ATCC 8503 & Escherichia coli $\mathrm{O} 157: \mathrm{H7}$ & ATCC 35150 \\
\hline Bacteroides fragilis & ATCC 25285 & Escherichia coli O70:K:H42 & ATCC 23533 \\
\hline Bacteroides thetaiotaomicron & ATCC 29741 & Escherichia fergusonii & ATCC 35469 \\
\hline Bacteroides vulgatus & ATCC 29327 & Escherichia hermannii & ATCC 33650 \\
\hline Bifidobacterium adolescentis & ATCC 15703 & Escherichia vulneris & ATCC 33821 \\
\hline Bifidobacterium bifidum & ATCC 29521 & Eubacterium rectale & ATCC 33656 \\
\hline Bordetella bronchiseptica & ATCC 19395 & Finegoldia magna & ATCC 29328 \\
\hline Bordetella holmesii & ATCC 51541 & Fluoribacter bozemanae & ATCC 33217 \\
\hline Bordetella parapertussis & ATCC 15311 & Fluoribacter gormanii & ATCC 33297 \\
\hline Bordetella pertussis & ATCC 9797 & Fusobacterium nucleatum & ATCC 25559 \\
\hline Burkholderia cepacia & SCB1277 & Gardnerella vaginalis & NYS 4-87 \\
\hline Campylobacter coli & ATCC 33559 & Giardia lamblia & ATCC 30957 \\
\hline Campylobacter jejuni & ATCC 33560 & Haemophilus influenzae & ATCC 10211 \\
\hline Chlamydia trachomatis & ATCC VR-348B & Human DNA & MRC- 5 cells \\
\hline Chlamydophila pneumoniae & ATCC 53592 & Klebsiella oxytoca & ATCC 700324 \\
\hline Chlamydophila pneumoniae & ATCC VR-1310 & Klebsiella pneumoniae & ATCC 700603 \\
\hline Citrobacter freundii & ATCC 8090 & $\begin{array}{c}\text { Lactobacillus delbrueckii ssp. } \\
\text { lactis }\end{array}$ & ATCC 12315 \\
\hline Clostridium difficile & ATCC 9689 & Lactobacillus rhamnosus & ATCC 7469 \\
\hline Clostridium perfringens & ATCC 13124 & Fluoribacter dumoffii & ATCC 33279 \\
\hline Clostridium ramosum & ATCC 25582 & Legionella jordanis & ATCC 33623 \\
\hline Collinsella aerofaciens & ATCC 25986 & Legionella longbeachae & ATCC 33462 \\
\hline Corynebacterium diphtheriae & SCB-25-86 & Tatlockia micdadei & ATCC 33204 \\
\hline $\begin{array}{l}\text { Corynebacterium } \\
\text { pseudodiphtheria }\end{array}$ & NY-4-88 & Legionella pneumophila & ATCC 33152 \\
\hline Cryptosporidium species & feline isolate & Legionella wadsworthii & ATCC 33877 \\
\hline Dientamoeba fragilis & ATCC 30948 & Listeria monocytogenes & ATCC 15313 \\
\hline Eggerthella lenta & ATCC 25559 & Moraxella catarrhalis & ATCC 8176 \\
\hline Encephalitozoon cuniculi & JS strain & Morganella morganii & CAP-D-5-79 \\
\hline Encephalitozoon hellem & ATCC 50451 & Mycobacterium africanum & ATCC 25420 \\
\hline Encephalitozoon intestinalis & ATCC 50651 & Mycobacterium avium & ATCC 700398 \\
\hline Mycobacterium avium & ATCC 700897 & Proteus mirabilis & ATCC 35659 \\
\hline Mycobacterium bovis & ATCC 19210 & Proteus vulgaris & QC strain \\
\hline Mycobacterium bovis (BCG) & ATCC 35735 & Pseudomonas aeruginosa & ATCC 27853 \\
\hline Mycobacterium gordonae & ATCC 14470 & Pseudomonas fluorescens/putida & CDC-AB4-B10-84 \\
\hline Mycobacterium intracellulare & ATCC 35761 & Rhodococcus equi & ATCC 6939 \\
\hline Mycobacterium kansasii & ATCC 12478 & Salmonella enterica & ATCC 35987 \\
\hline Mycobacterium microti & ATCC 19422 & Salmonella serogroup B & CAP-D-1-69 \\
\hline Mycobacterium smegmatis & ATCC 19980 & Shigella dysenteriae & CDC 82-002-72 \\
\hline Mycobacterium tuberculosis & ATCC 25177 & Shigella flexneri serotype 2a & ATCC29903 \\
\hline
\end{tabular}


TABLe 2: Continued.

\begin{tabular}{|c|c|c|c|}
\hline Organism & $\begin{array}{c}\text { Accession no. or } \\
\text { source }\end{array}$ & Organism & $\begin{array}{c}\text { Accession no. or } \\
\text { source }\end{array}$ \\
\hline Mycobacterium tuberculosis & ATCC 27294 & Shigella sonnei & ATCC 25931 \\
\hline Mycobacterium tuberculosis & ATCC 35825 & Staphylococcus aureus & ATCC 25923 \\
\hline Mycobacterium tuberculosis & ATCC 35837 & Staphylococcus epidermidis & ATCC 14990 \\
\hline Mycoplasma arginini & ATCC 23838D & Stenotrophomonas maltophilia & SCB-33-77 \\
\hline Mycoplasma arthritidis & ATCC 19611D & Streptococcus bovis & CAP-D-16-83 \\
\hline Mycoplasma bovis & ATCC 25523D & Streptococcus pneumoniae & ATCC 49619 \\
\hline Mycoplasma buccale & ATCC 23636 & Streptococcus pyogenes & ATCC 19615 \\
\hline Mycoplasma faucium & ATCC 25293 & Streptococcus sanguinis & ATCC 10556 \\
\hline Mycoplasma fermentans & ATCC 19989 & ${ }^{*}$ Ureaplasma parvum & ATCC 28715 \\
\hline Mycoplasma genitalium & ATTC 33530 & ${ }^{*}$ Ureaplasma urealyticum & ATCC 27618 \\
\hline${ }^{*}$ Mycoplasma hominis & ATCC 23114 & Yersinia enterocolitica & ATCC 9610 \\
\hline Mycoplasma hyorhinis & ATCC 17981D & BK polyomavirus & ATCC VR-837 \\
\hline Mycoplasma lipophilum & ATCC 27104 & Cytomegalovirus & ATCC VR-538 \\
\hline Mycoplasma orale & ATCC 23714 & & \\
\hline Mycoplasma phocidae & ATCC 33657 & Herpes simplex virus 1 & Lab Control \\
\hline Mycoplasma pirum & ATCC 25960D & Herpes simplex virus 2 & Lab Control \\
\hline Mycoplasma pneumoniae & ATCC 15531D & Human adenovirus 9 & ATCC VR-1086 \\
\hline Mycoplasma salivarium & ATCC 23064 & Human coronavirus 229E & ATCC VR-740 \\
\hline Neisseria gonorrhoeae & ATCC 43069 & $\begin{array}{c}\text { Human coxsackievirus B } 1 \\
\text { (Enterovirus })\end{array}$ & ATCC VR-28 \\
\hline Neisseria lactamica & ATCC 23970 & Human herpesvirus 6B & ATCC VR-1467 \\
\hline Neisseria meningitidis & ATCC 13077 & Human herpesvirus 7 & ABI 08765000 \\
\hline Nocardia brasiliensis & ATCC 51512 & Human herpesvirus 8 & ABI 08735000 \\
\hline Nocardia brevicatena & ATCC 15333 & Human parainfluenza virus 1 & ATCC VR-94 \\
\hline Nocardia carnea & ATCC 6847 & Human parainfluenza virus 3 & ATCC VR-93 \\
\hline Nocardiopsis dassonvillei & ATCC 23218 & Respiratory syncytial virus A2 & ATCC VR-1540 \\
\hline Nocardia farcinica & ATCC 3318 & Respiratory syncytial virus B & ATCC VR-1401 \\
\hline Nocardia otitidiscaviarum & ATCC 14629 & Influenza A virus (H3N2) & ATCC VR-810 \\
\hline Nocardia transvalensis & ATCC 6865 & Influenza B virus & ATCC VR-791 \\
\hline Plesiomonas shigelloides & ATCC 14029 & Measles virus & ATCC VR-24 \\
\hline Porphyromonas gingivalis & ATCC 33277 & Mumps virus & ATCC VR-365 \\
\hline Prevotella melaninogenica & ATCC 25845 & Varicella-zoster virus & ATCC VR-1367 \\
\hline Prevotella oralis & ATCC 33269 & & \\
\hline
\end{tabular}

\begin{tabular}{|c|c|}
\hline & Sequence $5^{\prime}-3^{\prime}$ \\
\hline U. urealyticum & $\begin{array}{ll}\text { ureC 158fl } & \text { ureC 158iLC610 } \\
\text { AGCAACTGTTAATGCTAAGTCAATAGCGTTTCCTG - - GCCCCTCAGTCTTCGTGAATCTTAAGACCACAAGC }\end{array}$ \\
\hline U. parvum & $\ldots \ldots \ldots \ldots$.А. \\
\hline
\end{tabular}

FIGURE 2: Ureaplasma probe design. 
TABLE 3: Comparison of PCR with culture for Mycoplasma hominis and Ureaplasma species detection.

\begin{tabular}{lcccc}
\hline & & \multicolumn{3}{c}{ M. hominis culture } \\
& & Positive & Negative \\
\hline \multirow{3}{*}{ M. hominis PCR } & Positive & 38 & 2 & 40 \\
& Negative & 4 & 239 & 243 \\
& & 42 & 241 & 283 \\
\hline
\end{tabular}

Sensitivity $=90.5 \%$ (95\% CI: 77.4\%, 97.3\%), specificity $=99.2 \%$ (95\% CI: 97.0\%, 99.9\%)

\begin{tabular}{lcccc}
\hline & & \multicolumn{3}{c}{ Ureaplasma species culture } \\
& & Positive & Negative & \\
\hline \multirow{3}{*}{ Ureaplasma PCR } & Positive & $139^{1}$ & $9^{2}$ & 148 \\
& Negative & 5 & 130 & 135 \\
& & 144 & 139 & 283 \\
\hline
\end{tabular}

Sensitivity $=96.5 \%$ (95\% CI: 92.1\%, 98.9\%), specificity $=93.5 \%$ (95\% CI: 88.1\%, 97.0\%)

${ }^{1} U$. urealyticum $(n=28), U$.parvum $(n=109)$, U. urealyticum and $U$.parvum (2).

${ }^{2} U$. urealyticum $(n=3)$, U. parvum $(n=6)$.

(U. parvum) and bases 40 through 520 of GenBank L08642.1 (U. urealyticum).

\section{Discussion}

We describe two rapid real-time PCR assays, one for detection of M. hominis and the other for detection of Ureaplasma species; they have comparable performance to culture but yield results in three hours, instead of two to five days for culture. These assays are performed on a standard platform and are adaptable to automation, a potential advantage over other described methods, especially for large reference laboratories that process large numbers of specimens.

We are not aware of other real-time PCR studies that have assessed M. hominis and Ureaplasma species using the same set of clinical samples. Overall, $14 \%$ of tested specimens were PCR positive for M. hominis and 52\% for Ureaplasma species. A multiplex PCR enzyme-linked immunosorbent assay was used to detect $M$. hominis and $U$. parvum and urealyticum in cervical swabs from 175 Australian women with and without cervicitis; $16 \%$ tested positive for $M$. hominis and 68\% for Ureaplasma species [15]. Multiplex PCR and autocapillary electrophoresis were used to detect $M$. hominis and Ureaplasma species (without differentiating $U$. parvum from urealyticum) in genitourinary specimens from 113 South Koreans with sexually transmitted infections; $12 \%$ were positive for $M$. hominis and $43 \%$ for Ureaplasma species [16]. These findings are similar to ours $[15,16]$.

Our PCR assay not only detects Ureaplasma species but also differentiates $U$. parvum from urealyticum. As in prior studies, U. parvum was more common than U. urealyticum, $[10,11,15,17]$ with $41 \%$ of the genitourinary specimens testing positive for the former and $12 \%$ for the latter. In one prior study, $63 \%$ of specimens were positive for U. parvum and $7 \%$ for U. urealyticum [15]. Another study showed, using a multiplex PCR-reverse line blot assay, that $48 \%$ of first voided urine specimens from women attending sexual health clinics in Australia were positive for U. parvum and $25 \%$ for U. urealyticum [17]. In the study by Tang et al., 36\% of genitourinary swabs collected from hospitalized males and females in China were positive for U. parvum and $8 \%$ for $U$. urealyticum [10]. Finally, in study by Vancutsem et al., $44 \%$ of lower genital tract specimens obtained from healthy women at their first prenatal visit in Belgium were positive for $U$. parvum and $10 \%$ for U. urealyticum [11]. Despite different geographic locales and clinical status, these numbers are strikingly similar.

In addition to the advantage of speed, the described assays overcome the challenges of detection of these organisms by culture. Although culture is considered a gold standard method (and was so considered in this study), colonial identification is challenging and subjective because it is done using the human eye and a dissecting microscope. Artifacts may be misidentified as colonies, yielding false-positive results, or colonies may be overlooked, yielding false-negative results. Although PCR may be considered more technically complex, in a laboratory where technologists are familiar with PCR, this approach is more user-friendly (and generalizable among assays for various microorganisms) than culture.

The described assays may be useful for investigating epidemiology and pathogenesis of infections with U. parvum and urealyticum $[2,18]$. Although extra-genital specimens were not tested, the described $M$. hominis assay may be useful to detect extra-genital M. hominis infections [7].

\section{Acknowledgments}

The authors thank Emily A. Vetter and Daniel R. Gustafson for their thoughtful reviews of this paper and assistance with the described studies and Dr. Kathleen A. Stellrecht at the Albany Medical Center for assistance with testing of discrepant results. This work was presented in part at the 48th Annual Infectious Diseases Society of America Meeting, 2010.

\section{References}

[1] D. Taylor-Robinson and J. S. Jensen, "Mycoplasma genitalium: from chrysalis to multicolored butterfly," Clinical Microbiology Reviews, vol. 24, no. 3, pp. 498-514, 2011.

[2] M. A. Patel and P. Nyirjesy, "Role of Mycoplasma and Ureaplasma species in female lower genital tract infections," Current Infectious Disease Reports, vol. 12, no. 6, pp. 417-422, 2010.

[3] R. Aaltonen, J. Jalava, E. Laurikainen, U. Kärkkäinen, and A. Alanen, "Cervical Ureaplasma urealyticum colonization: comparison of PCR and culture for its detection and association with preterm birth," Scandinavian Journal of Infectious Diseases, vol. 34, no. 1, pp. 35-40, 2002.

[4] J. A. Robertson, G. W. Stemke, J. W. Davis et al., "Proposal of Ureaplas maparvum sp. nov. and emended description of Ureaplasma urealyticum (Shepard et al. 1974) Robertson et al. 2001," International Journal of Systematic and Evolutionary Microbiology, vol. 52, no. 2, pp. 587-597, 2002. 
[5] A. Baczynska, H. F. Svenstrup, J. Fedder, S. Birkelund, and G. Christiansen, "Development of real-time PCR for detection of Mycoplasma hominis," BMC Microbiology, vol. 4, article 35, 2004.

[6] C. Férandon, O. Peuchant, C. Janis et al., "Development of a real-time PCR targeting the yidC gene for the detection of Mycoplasma hominis and comparison with quantitative culture," Clinical Microbiology and Infection, vol. 17, no. 2, pp. 155159, 2011.

[7] A. Pascual, K. Jaton, B. Ninet, J. Bille, and G. Greub, "New diagnostic real-time PCR for specific detection of Mycoplasma hominis DNA," International Journal of Microbiology, vol. 2010, Article ID 317512, 4 pages, 2010.

[8] L. Xiao, J. I. Glass, V. Paralanov et al., "Detection and characterization of human Ureaplasma species and serovars by real-time PCR," Journal of Clinical Microbiology, vol. 48, no. 8, pp. 27152723, 2010.

[9] J. Yi, H. Y. Bo, and E. C. Kim, "Detection and biovar discrimination of Ureaplasma urealyticum by real-time PCR," Molecular and Cellular Probes, vol. 19, no. 4, pp. 255-260, 2005.

[10] J. Tang, L. Zhou, X. Liu, C. Zhang, Y. Zhao, and Y. Wang, "Novel multiplex real-time PCR system using the SNP technology for the simultaneous diagnosis of Chlamydia trachomatis, Ureaplasma parvum and Ureaplasma urealyticum and genetic typing of serovars of C. trachomatis and U. parvum in NGU," Molecular and Cellular Probes, vol. 25, no. 1, pp. 55-59, 2011.

[11] E. Vancutsem, O. Soetens, M. Breugelmans, W. Foulon, and A. Naessens, "Modified real-time PCR for detecting, differentiating, and quantifying Ureaplasma urealyticum and Ureaplasma parvum," Journal of Molecular Diagnostics, vol. 13, no. 2, pp. 206-212, 2011.

[12] K. A. Stellrecht, A. M. Woron, N. G. Mishrik, and R. A. Venezia, "Comparison of multiplex PCR assay with culture for detection of genital mycoplasmas," Journal of Clinical Microbiology, vol. 42, no. 4, pp. 1528-1533, 2004.

[13] F. Kong, Z. Ma, G. James, S. Gordon, and G. L. Gilbert, "Species identification and subtyping of Ureaplasma parvum and Ureaplasma urealyticum using PCR-based assays," Journal of Clinical Microbiology, vol. 38, no. 3, pp. 1175-1179, 2000.

[14] T. Baracaldo, M. Foltzer, R. Patel, and P. Bourbeau, "Empyema caused by Mycoplasma salivarium," Journal of Clinical Microbiology, vol. 50, no. 5, pp. 1805-1806, 2012.

[15] C. J. McIver, N. Rismanto, C. Smith et al., "Multiplex PCR testing detection of higher-than-expected rates of cervical Mycoplasma, Ureaplasma, and Trichomonas and viral agent infections in sexually active australian women," Journal of Clinical Microbiology, vol. 47, no. 5, pp. 1358-1363, 2009.

[16] Z. Samra, S. Rosenberg, and L. Madar-Shapiro, "Direct simultaneous detection of 6 sexually transmitted pathogens from clinical specimens by multiplex polymerase chain reaction and auto-capillary electrophoresis," Diagnostic Microbiology and Infectious Disease, vol. 70, no. 1, pp. 17-21, 2011.

[17] M. L. McKechnie, R. J. Hillman, R. Jones et al., “The prevalence of urogenital micro-organisms detected by a multiplex PCRreverse line blot assay in women attending three sexual health clinics in Sydney, Australia," Journal of Medical Microbiology, vol. 60, no. 7, pp. 1010-1016, 2011.

[18] Y. A. Barykova LD, M. M. Shmarov, A. Z. Vinarov et al., "Association of Mycoplasma hominis infection with prostate cancer," Oncotarget, vol. 2, no. 4, pp. 289-297, 2011. 

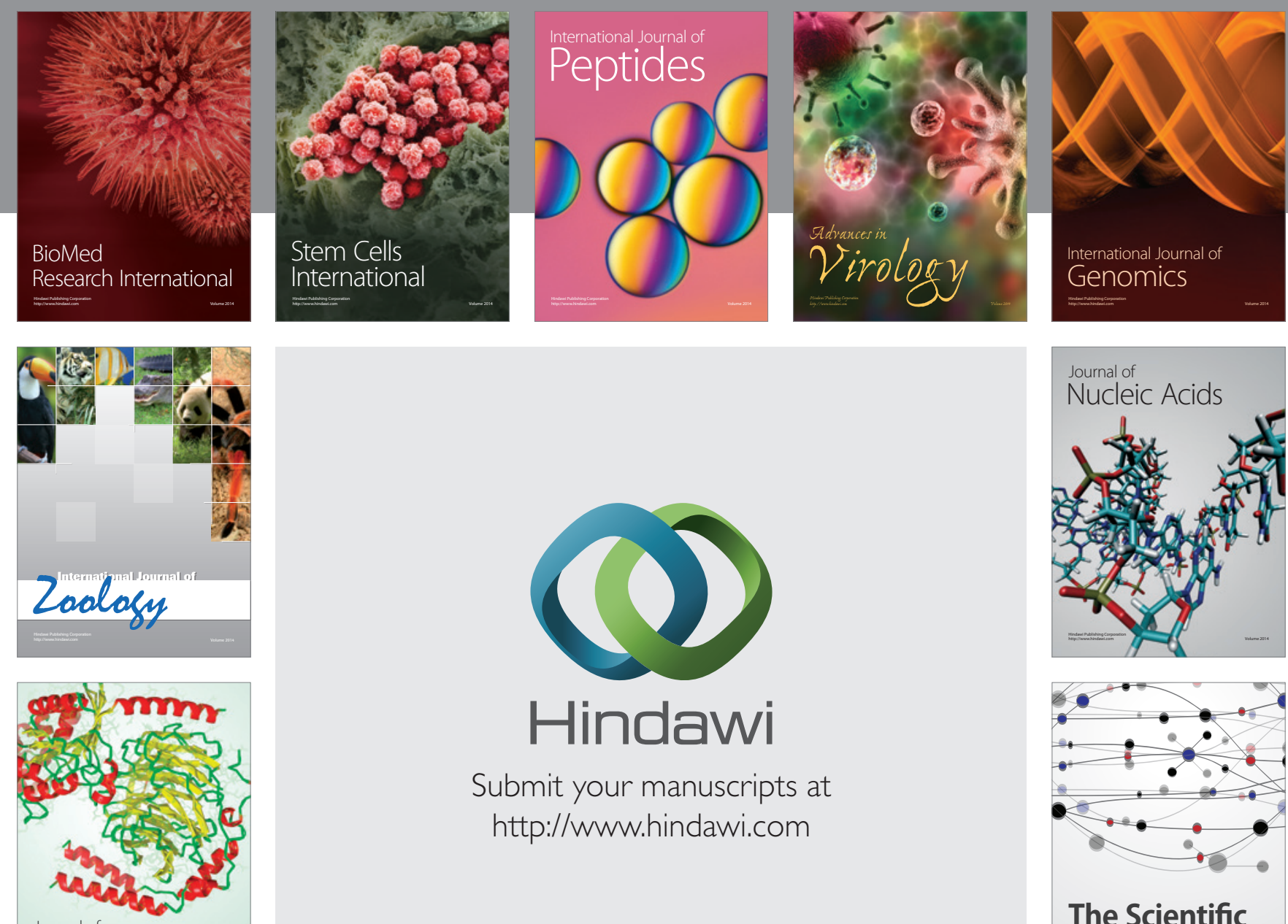

Submit your manuscripts at

http://www.hindawi.com

Journal of
Signal Transduction
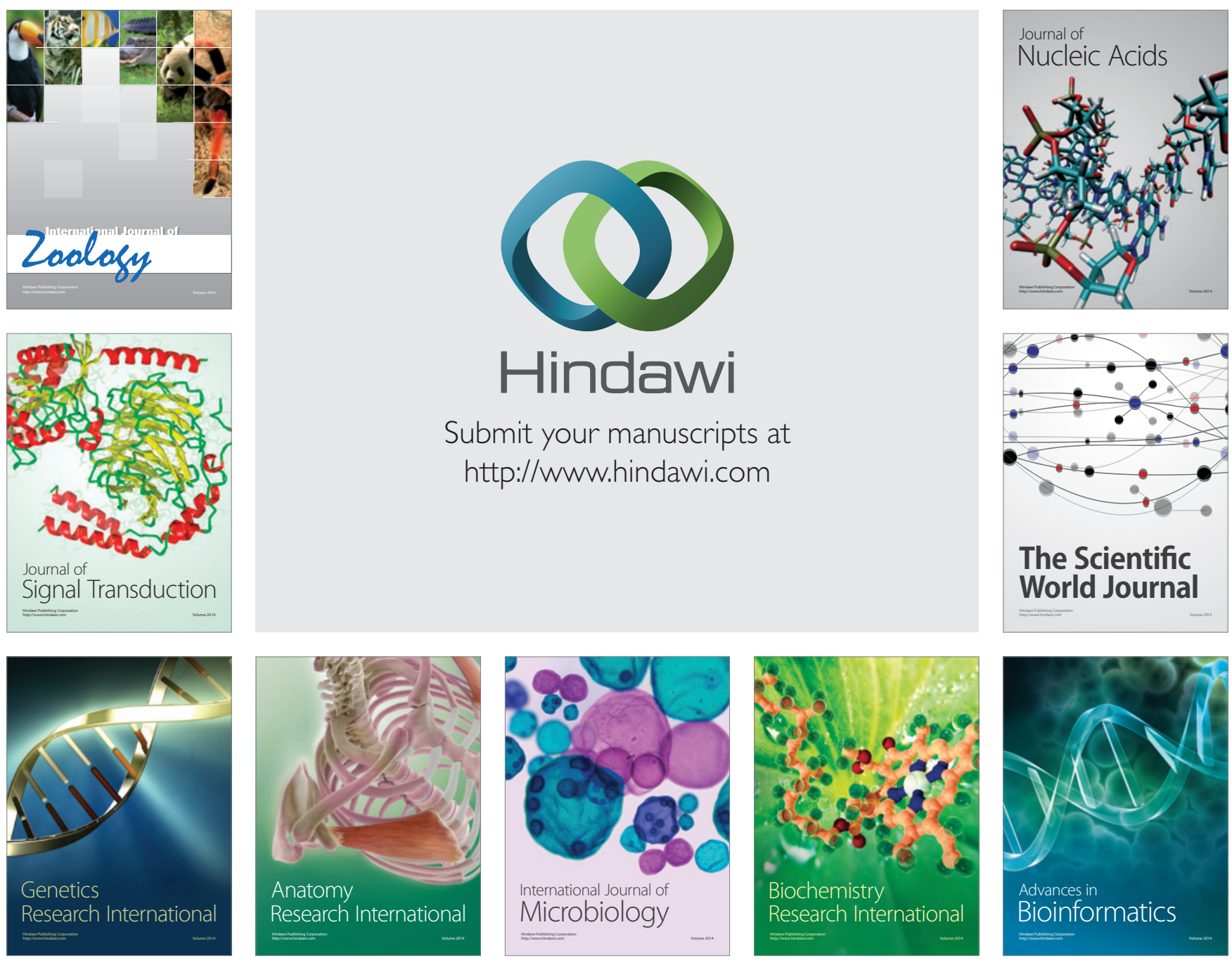

The Scientific World Journal
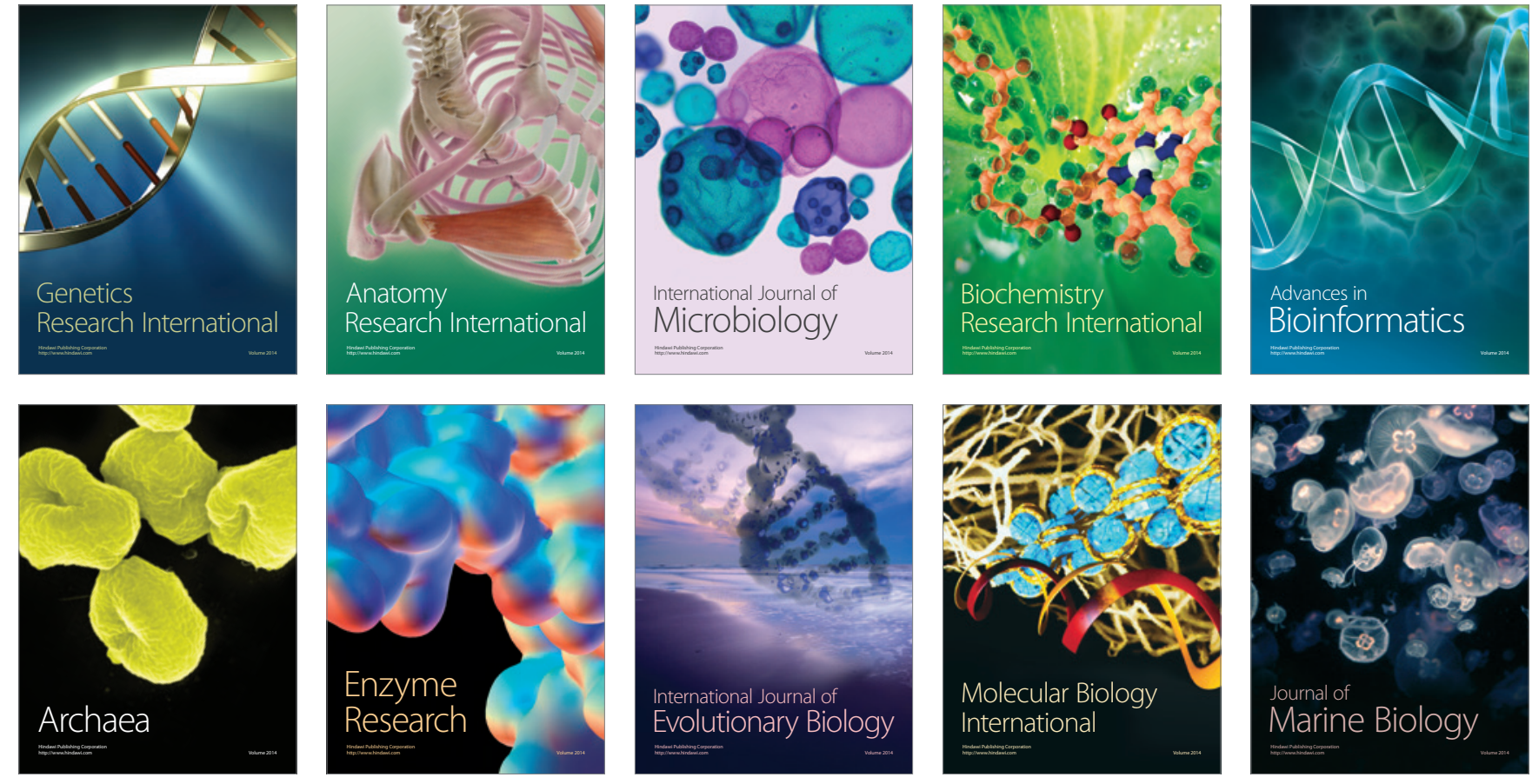